\title{
Administração de conflitos, espaço público e cidadania Uma perspectiva comparada
}

\author{
Roberto Kant de Limal
}

Este trabalho pretende argumentar que a oposição público/privado, freqüentemente utilizada para analisar dados e propor interpretações referentes às relações entre a sociedade e o estado, os indivíduos e a coletividade e/ou a esfera pública e o domínio das relações de privacidade, em muito ganharia, do ponto de vista heurístico, se incorporasse as oposições entre o âmbito geral e/ou local e a aplicação universal e/ou particular das regras que regem os espaços públicos, esclarecedoras de outras dimensões da sociedade que nos são reveladas pelo método comparativo, da maneira como é exercido na antropologia contemporânea.

Os Estados Unidos, deste ponto de vista, se apresentam para nós como uma referência comparativa potencialmente frutífera, por suas semelhanças estruturais com nossa sociedade, inscritas não só em nossas estruturas políticas, mas também por suas características, também capitalistas, também situadas no Novo Mundo, mas tão distintas das nossas em termos de seus modelos jurídicos e políticos de controle social. Modelos que se explicitam tanto nas doutrinas, códigos e leis, como também em nosso dia a dia, nas cotidianas práticas de administrar disputas e promover acordos que fazem parte da vida social de qualquer grupo. Tais diferen-

\footnotetext{
${ }^{1}$ Jurista e antropólogo, professor titular de Antropologia da UFF, bolsista da Faperj e de produtividade 1-A do CNPq. Autor de A antropologia da academia: quando os índios somos nós (Edit. UFF). Contatos com o autor: kant@web4u.com.br.
} 
ças, digamos assim, de tradições, ou sensibilidades legais ${ }^{2}$ que, explícita ou implicitamente, pretendem produzir a verdade e administrar conflitos no espaço público, saltam aos olhos quando dirigimos mesmo um rápido olhar para os modelos de controle social enfatizados no Brasil e nos Estados Unidos, elaborados no âmbito dos respectivos sistemas jurídicos, e que mostram desde logo quão diferentes podem ser os princípios que informam a construção e o funcionamento desses modelos.

Num primeiro modelo, aquele explicitamente enfatizado nos Estados Unidos, o espaço público Bem inglês, public B aparece como um espaço coletivo, negociado pelo público que dele faz parte, que pertence ao local e que se compromete a conviver com as diferenças "normais", quer dizer, aquelas que foram explicitamente discutidas e aceitas num sistema de segregação dos iguais, mas diferentes, que procura, assim, prevenir explicitamente o conflito latente entre indivíduos únicos com interesses divergentes. A imagem com que essa sociedade prefere se representar é aquela de um paralelepípedo, em que a base é igual ao topo e todos, separadamente, têm direito à mesma trajetória, desigualmente trilhada por cada um dadas suas próprias condições de habilitação e capacitação. Como diz Roberto DaMatta, todos separados, mas juntos. ${ }^{3}$

Neste modelo o campo do direito tende a identificar direito, regras sociais e prescrições morais, enquanto constituintes de um sistema de normas geralmente aprovado pela maioria como adequado para o comportamento social em geral. A desobediência à lei e, por extensão, a qualquer regra social será identificada socialmente como uma transgressão moral, uma ruptura de um genérico e abstrato contrato social, uma agressão, não a um Estado distante e impessoal, mas aos direitos de outros indivíduos caracterizados como "próximos" física e moralmente, genérica e formalmente iguais, que se estão esforçando para conviver com a diferença alheia.

O que "cola" este sistema de representações é a idéia que ele produz de si mesmo como um mercado de opções, cuja eficácia está fundamentada no acesso universal Bquer dizer, de forma igual para todos os "consumidores"B às informações sobre os "produtos" disponíveis. Este acesso é a garantia da previsibilidade sobre a "normalidade" das escolhas, pois não se pode querer o que não está ofere-

${ }^{2}$ Geertz, Clifford, O saber local: fatos e leis em uma perspectiva comparada. In: Clifford Geertz, Conhecimento local. Petrópolis: Vozes, 1998: 249-356.

${ }^{3}$ DaMatta, Roberto, Você sabe com quem está falando? In: Roberto DaMatta, Carnavais, malandros e heróis. Rio de Janeiro: Zahar, 1979:139-193. 
cido explicitamente no mercado. É um sistema em que opções diferenciadas das disponíveis são sistematicamente classificadas como desvios da norma(lidade).

Como conseqüência, exige-se que o que é explicitado ao público seja verdadeiro, para que as opções possam ser feitas com conhecimento de causa e haja previsibilidade do comportamento coletivo. O segredo, o saber de acesso particularizado, a informação privilegiada, são elementos profundamente disruptores desse sistema e não podem e não devem produzir resultados válidos, sendo perseguidos e eliminados aonde se manifestarem, como representantes confessos do privilégio e da hierarquia excludente. Só é válida em público a informação a que todos têm acesso, sob pena de instaurar-se o caos.

Já no Brasil, ao contrário, o modelo enfatizado pelo sistema jurídico não reivindica uma origem "popular" ou "democrática" para a legitimação de sua existência. Ao contrário, alega ser o produto de uma reflexão iluminada, uma "ciência normativa", que tem por objetivo o controle de uma população sem educação, desorganizada e primitiva. Os modelos jurídicos de controle social, portanto, não têm nem poderiam ter como origem "a vontade do povo", enquanto reflexo das normas que regem seu estilo de vida, mas são resultado destas formulações legais especializadas, legislativa ou judicialmente. Nestas circunstâncias não é difícil compreender que, ao não ser considerada como fórmula ideal a "aplicação da lei pelo povo", valores legais, quando se aplicam, tendem a ser vistos como constrangimentos externos ao comportamento dos indivíduos. Em conseqüência, o capital simbólico do campo do direito não reproduz ampliadamente seu valor porque expressa a "vontade do povo", ou um conjunto de prescrições morais partilhadas e internalizadas pelo cidadão comum, mas como uma imposição das "autoridades", não importa quão legal e legitimadamente produzidas e postas em vigor.

Embora este modelo se assemelhe àquele da civil law tradition, que opera com "códigos" legais legitimados pelo Poder Legislativo, a serem decifrados pelos juristas, difere dele pela sua ênfase em processos de "inquirição" como a melhor forma de estabelecer a verdade e evitar a explicitação de conflitos na sociedade. Nesta versão do sistema de produção de verdades judiciárias, existe uma valorização positiva explícita do segredo, do conhecimento detido de forma particular, não universalmente disponível na sociedade: quem pergunta sempre sabe mais do que quem responde e é deste saber prévio que advém a autoridade do seu discurso. Decorrem daí, inclusive, regimes retóricos distintos daqueles da argumentação que busca o consenso: aqui predomina o embate escolástico de teses opostas, em que apenas uma deve ganhar, por ter saber mais autoritativo do que o da outra. Vale o argumento de autoridade, em prejuízo da autoridade dos argumentos. 
Neste contexto, a obediência ou a desobediência às leis e regras que regem a apropriação e uso dos espaços públicos não se coloca como questão de transgressão moral a regulamentos explícitos facilmente acessíveis, a serem literalmente interpretados, mas como o resultado da escolha entre a liberdade de agir e o constrangimento externo, a opção entre a implementação do desejo individual e da reprodução social de cada um, por um lado, e a submissão a um interesse geral e difuso, quase certamente manipulado em beneficio da reprodução alheia, por outro.

Como conseqüência, aqui, o domínio do público, a res publica, a "coisa pública", contraditoriamente ao domínio da sociedade, não é representado como o locus da regra local e explícita, de aplicação universal, a todos acessível e, portanto, a todos aplicável por igual, que é a condição indispensável e necessária para a interação social entre indivíduos diferentes mas iguais, de acordo com a representação anglo-americana da sociedade que, explicitamente, é enfatizada naquele sistema. Ao contrário, a ênfase jurídica na definição do domínio do público, seja moral, intelectual ou até mesmo o espaço físico, é a de que este é o lugar controlado pelo Estado, de acordo com "suas" regras. Neste espaço tudo é possivelmente permitido, até que seja proibido ou reprimido pela "autoridade", que tem acesso não só ao conteúdo das regras mas, principalmente, a competência para a interpretação correta da aplicação particularizada das prescrições gerais, sempre realizada através de formas implícitas e de acesso privilegiado. ${ }^{4}$ Por oposição ao modelo do paralelepípedo, temos aqui a representação de um modelo piramidal, em que a desigualdade é natural. ${ }^{5}$

O domínio público, assim, é o lugar apropriado particularizadamente, seja pelo Estado, seja por outros membros da sociedade, autorizados ou não por ele, e, por isso, sempre, aparentemente, opaco, caótico e imprevisível ao olhar coletivo, onde tudo pode acontecer e de onde "quero tudo o que tenho direito", significando não só que reivindico aquilo que sei merecer, mas que desejo ter, substantivamente, tudo o que os outros têm e cujo conteúdo e significação, eventualmente, posso até mesmo desconhecer. A liberdade, neste contexto, não é associada à liberdade

${ }^{4}$ Este é o caso, por exemplo, dos efeitos imprevisíveis que podem ter as coisas "publicadas" no Diário Oficial, que todos têm a "obrigação" de saber e que podem, inclusive, levar alguém a ser julgado e condenado à revelia, isto é, sem que nem mesmo tenha sido pessoalmente informado que está sendo alvo de uma acusação.

${ }^{5}$ É claro que os dois sistemas Bo do paralelepípedo e o da pirâmideB estão presentes em todos os sistemas jurídico-políticos contemporâneos de administração institucional de conflitos, pelo menos no ocidente. Por isso, friso que tais modelos são enfatizados em determinados locais e circunstâncias de cada sociedade empírica sob análise. 
de escolher no mercado onde as opções dadas foram previamente negociadas, como no sistema anglo-americano, mas à possibilidade aberta de todos poderem "ter" tudo. A idéia de igualdade, assim, torna-se substantiva, associada à semelhança, não à diferença, entre as pessoas. Neste contexto, as negociações se tornam deslocamentos estruturais, que afetam posições desiguais em uma hierarquia excludente, não composições que visam à produção de uma hierarquia social includente, de um rank.

O espaço público, nesta versão, tem que estar sempre submetido a regras gerais, nunca locais. Neste sentido, é semelhante ao space publique francês, onde o sistema de controle social também rejeita a estratégia das minorias segregadas com lugares diferenciados para preservar a igualdade formal. Estas regras, que não se originam dos cidadãos envolvidos nos conflitos, como devem ser aplicadas particularizadamente, pressupõem uma competição entre os envolvidos pelo favorecimento de sua aplicação e uma suposta neutralidade do aplicador em relação às partes. O sistema, assim, coloca todos juntos, mas separados e hierarquizados na conquista dos melhores lugares em uma estrutura que pode ser representada como piramidal. E como toda estrutura hierarquizada, piramidal, constituída de partes desiguais mas complementares, esta rejeita a explicitação do conflito, uma força disruptora que ameaça desarrumá-la. Quem está no topo, no vértice, é o único que tudo vê, cuja perspectiva é a verdadeira, pois os demais elementos têm apenas visões parciais do conjunto, tanto mais distorcidas quanto mais próximos à base se encontrem. Só vale a pena saber aquilo que poucos sabem, pois só assim tenho a garantia de obter efeitos confiáveis; a informação a que todos têm acesso de nada vale.

Diferentemente do sistema francês, no entanto, há em nosso modelo espaço para o reconhecimento explícito da desigualdade entre os cidadãos, manifestada em nosso dia a dia pelos rituais do "Você sabe com quem está falando?" e, mesmo, no reconhecimento jurídico a direitos diferentes explicitamente atribuídos a pessoas supostamente desiguais, como é o caso dos privilégios concedidos oficialmente a certas categorias de cidadãos pelo instituto da prisão especial.

O que possibilita, portanto, a ordem social em um sistema, que se constrói a partir da explicitação dos conflitos de interesses individualizados, em franca oposição, gerando a construção coletiva de regras explícitas, de aplicação literal e universal, o que se constitui em legitimação de sua ordem jurídica, em que a concepção de igualdade é formal $\mathbf{B}$ o direito igual de todos à diferença, é o que dificulta a existência do outro, fundado na conciliação forçada dos conflitos, visando a imposição da harmonia e do status quo, para manter a hierarquia e a complementaridade entre elementos substantivamente diferenciados do sistema, 
produtor de regras gerais, sempre interpretadas particularizadamente pelos detentores do saber privilegiado para fazer justiça adequada a todos esses segmentos diferenciados.

No primeiro sistema, o acesso universal à informação se constitui na base do controle social, no fator normalizador da sociedade: visa-se não só a repressão das diferenças inaceitáveis, mas o controle da população pela imposição de uma homogeneidade construída pela normalização pela informação: o objetivo do sistema é a naturalização da igualdade pela neutralização das desigualdades, definidas como meras diferenças. No segundo sistema, o acesso particularizado à informação é o que define a hierarquia das interpretações e as redes de sociabilidade responsáveis pela compensação das desigualdades de toda sorte, assim naturalizadas e reconhecidas explicitamente como inevitáveis na sociedade. ${ }^{6}$.

Em nossa sociedade esta tradição jurídica particularista coexiste, aparentemente, com os anseios de universalidade de uma cultura jurídico-política explícita, de caráter individualista e igualitário, que precisa fundar-se em mecanismos universais de administração de conflitos pela produção de verdades negociadas. Ao contrário da tradição dos Estados Unidos, onde os princípios processuais são constitucionais e disponíveis, aplicando-se universal e localmente, a tensão entre o político e o jurídico, entre o constitucional e o judicial, cada vez mais, se faz presente em nossa sociedade, opondo uma concepção de generalidade fundada em diferenças substantivas entre as pessoas e as coisas, próprias dos sistemas hierárquicos e particularistas, a uma universalidade fundada na aplicação local de regras consensuais e na estratificação das igualdades formais, própria dos sistemas individualistas. É como se tivéssemos, juridicamente, uma pirâmide sobreposta a um paralelepípedo. A questão relevante que se coloca, portanto, não é apenas a das contradições entre as formas de apropriação e uso do público e do privado mas, principalmente, entre os sistemas interpretativos de aplicação particularista de regras gerais, ou aqueles de aplicação universalista de regras locais e literais.

${ }^{6}$ Não será por coincidência que os contrastes entre os sistemas de educação fundamental no Brasil e nos EUA são tão marcantes, evidenciando lá suas raízes protestantes, em que a capacidade para a leitura e o argumento do acesso universal e literal aos textos sagrados e, consequentemente, àqueles responsáveis pela ordem na sociedade, são requisitos indispensáveis para a incorporação dos segmentos reconhecidamente diferenciados da população e para a compreensão do seu papel e responsabilidade na administração e controle da diversidade dos homens no mundo. Enquanto no Brasil, onde constitucionalmente todos são iguais perante a lei, a educação superior concede privilégios de presunção da inocência a quem a detém, em prejuízo da presunção da culpa daqueles que dela são, literalmente, excluídos. 